\title{
Promoção da equidade de gênero por meio de ações extensionistas das Meninas Digitais no Cerrado em tempos de Pandemia
}

\author{
Maria Isabela Silva Nunes \\ Instituto Federal Goiano - Campus Ceres \\ maria.isabela@estudante.ifgoiano.edu.br \\ Sara Luiz de Farias \\ Instituto Federal Goiano - Campus Ceres \\ sara.farias@estudante.ifgoiano.edu.br \\ Adriano Honorato Braga \\ Instituto Federal Goiano - Campus Ceres \\ adriano.braga@ifgoiano.edu.br
}

\author{
Thalia Santos de Santana \\ Instituto Federal Goiano - Campus Ceres \\ thalia.santana@ifgoiano.edu.br \\ Ramayane Bonacin Braga \\ Instituto Federal Goiano - Campus Ceres \\ ramayane.santos@ifgoiano.edu.br \\ Natália do Carmo Louzada \\ Instituto Federal Goiano - Campus Ceres \\ natalia.louzada@ifgoiano.edu.br
}

\begin{abstract}
The gender gap in the fields of science and technology is notorious. In Brazil, only $20 \%$ of information technology professionals are women, which highlights the necessity of activities to mitigate this instability and promote equity. With the pandemic, it was necessary for the project Meninas Digitais no Cerrado to readapt and plan new strategies to continue attracting girls and women to the area, thus changing mainly to exclusively non-presential actions, maintaining social distance. Thus, this work reports the female empowerment activities carried out in the Goias. The results of the virtual activities have shown to be of great impact, since the events are reaching participants from almost all Brazilian states, increasing the number of female participation in stimulation actions in favor of more women in computing and creating greater engagement among partner projects.
\end{abstract}

\section{KEYWORDS}

Woman in Computing, Gender, Empowerment, Informatics in Education.

\section{INTRODUÇÃO}

Estudos apontam uma diminuição do número de mulheres em Computação e Engenharias, áreas que representam menos de 5\% dos interesses de meninas como carreira profissional [1]. Estatísticas como essa, correlacionadas ao menor número de mulheres em cursos nível médio técnico em Informática (38\%) [2] e graduação em computação $(13,95 \%)$ no Brasil [3], reforçam o cenário de desequilíbrio de gênero em Tecnologia da Informação (TI).

Por conseguinte, instituições e empresas de todo o mundo, ao compreender a importância da diversidade e presença feminina no setor, vêm tecendo iniciativas [4-5] para mudar este panorama, criando projetos e campanhas para que mais mulheres conheçam a referida área e se interessem pela mesma.

Existem diversos fatores que afastam meninas e mulheres da computação. Pesquisas revelam que alunas do Curso Técnico em Informática Integrado ao Ensino Médio ainda não possuem uma visão ampla sobre a Computação, mantendo inclusive concepções fantasiosas e incorretas da área - mesmo já estando inseridas neste meio [6]. Em face a isso, acreditamos que devem ser buscadas soluções para incentivar mulheres a se interessar pelo tema da TI, e mesmo permanecer nos cursos escolhidos, tanto em nível médio quanto superior.

Nesse sentido, uma das estratégias é realizar ações e atividades tanto com recorte de gênero, quanto destinadas à sociedade ampla, a fim de que, desse modo, haja maior acesso ao conhecimento técnico-científico em TI, bem como maior visibilidade do êxito feminino no âmbito da ciência. Construindo assim uma sociedade com maior equidade de gênero, por meio da ressignificação do imaginário social das profissões relacionadas à Computação.

Para tanto, o projeto Meninas Digitais no Cerrado visa estimular a participação feminina nas áreas da ciência e tecnologia, por meio de ações no Instituto Federal Goiano Campus Ceres e em conjunto a projetos e eventos parceiros. Todavia, no contexto da pandemia de COVID-19, foi necessário se adaptar, realizando virtualmente as atividades que antes eram totalmente presenciais. De maneira que, neste estudo, serão descritas as ações extensionistas promovidas em tempos de distanciamento social, a fim de colaborar com o corpo de pesquisas relacionadas ao tema como um portfólio de sugestões de atividades para demais projetos e iniciativas.

O presente trabalho está assim estruturado: a Seção 2 apresenta os materiais e métodos empregados, com uma descrição de cada uma das atividades propostas, a Seção 3 discute os principais resultados alcançados com as ações on-line e a Seção 4, traz as considerações finais, seguidas das referências bibliográficas. 


\section{MATERIAIS E MÉTODOS}

O presente trabalho tem a intenção de apresentar as atividades de extensão desenvolvidas durante a pandemia, sendo parte destas organizadas pelo próprio grupo e algumas em parceria com outros projetos e programas, de outras Instituições de ensino. Devido à natureza remota das atividades, foram utilizadas plataformas online para a transmissão e execução das mesmas, como por exemplo o Instagram ${ }^{1}$ e o YouTube $^{2}$, visando prover maior interatividade e acessibilidade ao público.

Descrevemos abaixo cada uma das ações extensionistas que consideramos exitosas. Ademais, após a descrição da execução, trataremos ainda dos questionários, elaborados pela ferramenta Google Formulários ${ }^{3}$, e aplicados com a finalidade de apreender a percepção dos participantes ao avaliarem sua experiência no âmbito da ação desenvolvida.

\subsection{Ações e atividades promovidas}

Após a decisão de paralisação das aulas presenciais como medida de enfrentamento do Coronavírus, houve uma reunião com a equipe executora do projeto para discutir quais ações poderiam ser realizadas durante a pandemia, visando manter o vínculo das discentes com o projeto e Instituição por meio de acolhimento e apoio. Atualmente, o projeto é coordenado por quatro docentes, que atuam nos cursos Técnico em Informática para Internet Integrado ao Ensino Médio e Bacharelado em Sistemas de Informação, incluindo uma docente recém-graduada no referido bacharelado oferecido pelo campus. Há ainda três alunas do nível médio e duas da graduação, compondo o núcleo executor do grupo.

Após consulta com as discentes de nível médio e superior sobre seus interesses e sugestões para ações, uma série de atividades foram planejadas. Inicialmente, o público alvo foram estudantes da Instituição - incluindo, para além da informática, os demais cursos ofertados. Tais ações extrapolaram quaisquer barreiras geográficas, obtendo expressiva participação de demais estados brasileiros.

A primeira atividade elaborada foi o Curso de Canva Online, executado entre os dias 22 e 29 de maio de 2020, com o intuito de ensinar conhecimentos introdutórios para a criação de design por meio da plataforma $\mathrm{Canva}^{4}$. A capacitação foi realizada pelo Google Meet $^{5}$ (Fig. 1) e contou com mais de 250 inscrições de 14 estados do Brasil. Com tamanha proporção, o mesmo foi dividido em quatro turmas a fim de atender ao alto quantitativo de pessoas interessadas.

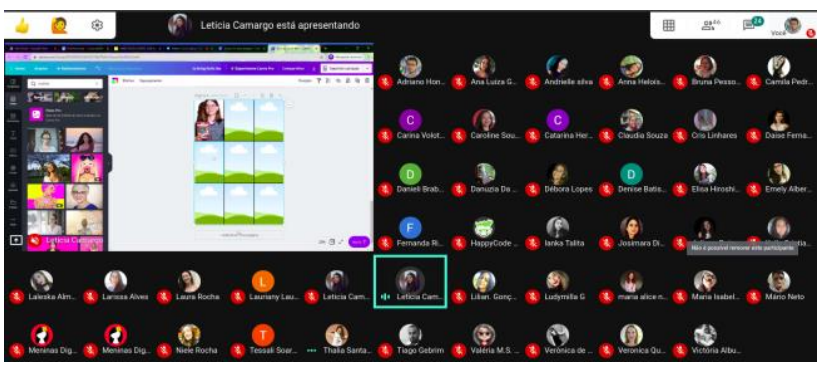

Figura 1: Aula do Curso de Canva. Fonte: Própria (2020).

Ao mesmo tempo, em maio de 2020 foram iniciadas as lives do "MDC em Casa". Ao todo ocorreram nove lives com duração de 60 minutos cada, que se estenderam até o mês de julho. As entrevistadas foram mulheres de diferentes projetos e Instituições, abordando temáticas tais como: Mulheres na computação, Segurança de Dados, Computação Desplugada, Projetos de Empoderamento Feminino, Biotecnologia, Estatística e áreas interdisciplinares com Computação.

A ação em questão alcançou todas as regiões do país pelo Instagram e YouTube. O projeto teve a intenção de estimular o contato de participantes e perfis femininos de sucesso em ciência e tecnologia, ainda que por intermédio do ambiente virtual. A divulgação ocorreu por meio das mídias sociais, tal como representado a seguir (Fig. 2). Outro ponto interessante da ação executada foi a grande participação de pessoas externas, não ligadas diretamente ao projeto, demonstrando uma das grandes vantagens percebidas com as atividades on-line: ampliação do alcance e do número de pessoas impactadas.

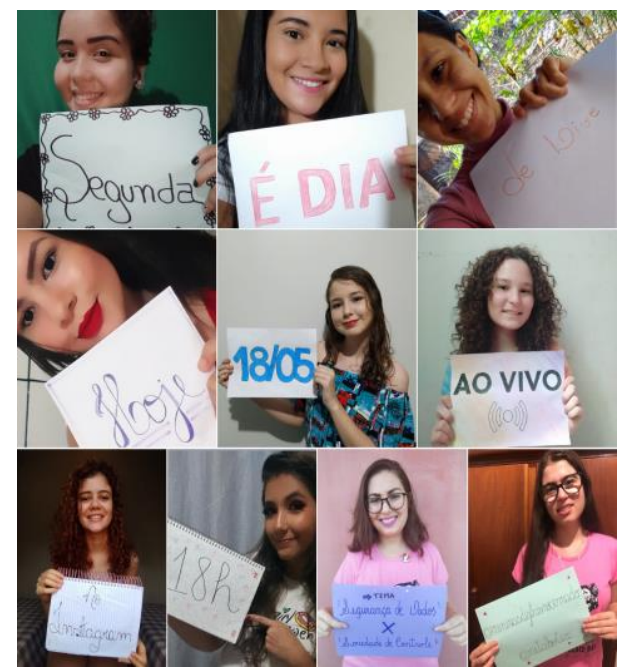

Figura 2: Estudantes divulgando o início do circuito de lives. Fonte: Própria (2020).

\footnotetext{
4 https://www.canva.com

5 https://meet.google.com/
}

\footnotetext{
https://www.instagram.com/

2 https://www.youtube.com/

3 https://docs.google.com/forms/u/0/
} 
Já no $2^{\circ}$ semestre, foi realizada a quarta edição de uma das atividades com maior destaque e tradição no âmbito do projeto: o Ada Lovelace Day On-line. Homenageando a primeira programadora da humanidade, o mesmo ocorreu no dia 20 de outubro, pelo YouTube, e contou com uma mesa redonda composta por estudantes do curso Técnico em Informática integrado ao Ensino Médio de diversos campi do Instituto Federal, projetando o protagonismo das discentes e suas perspectivas sendo meninas na área. Além disso, também houve a presença de duas palestrantes falando sobre suas experiências pessoais e profissionais na área da TI.

Outra ação de grande destaque, cuja oportunização foi realizada com maior fôlego, foi o curso de extensão on-line (Fig. 3) intitulado "Trabalhando o empoderamento feminino por meio da história das mulheres na computação". Somando uma carga horária total de $100 \mathrm{~h}$, o mesmo ofereceu três disciplinas centrais: "Introdução aos estudos feministas"; "História das mulheres na computação"; e "Pensamento computacional". O público alvo tratou-se de pessoas com ensino fundamental II completo e idade mínima de 14 anos. Dado o êxito de ações presenciais anteriores, tal como feito anteriormente, o curso on-line foi pensado em prol da comunidade externa. O mesmo contou com a ajuda de duas tutoras que compõem a equipe do projeto, com cadastro específico em editais institucionais, e continua em execução no momento de submissão do presente trabalho.

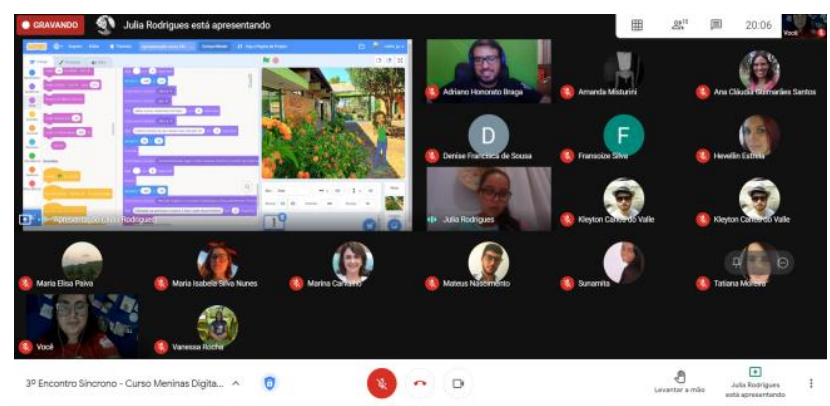

Figura 3: Encontro síncrono do Curso de Extensão On-line "Trabalhando o Empoderamento Feminino por meio da História das Mulheres na Computação". Fonte: Própria (2020).

No dia 18 de novembro o Meninas Digitais no Cerrado foi convidado a integrar um painel com o tema "Ações de Projetos Parceiros do Programa Meninas Digitais durante a Pandemia", durante o $14^{\circ}$ Women in Information Technolog $y^{6}$, dentre o Fórum Meninas Digitais, que trata do programa chancelado pela Sociedade Brasileira de Computação (SBC) [7]. O evento representa um dos principais espaços de troca de experiências da

\footnotetext{
6 http://www2.sbc.org.br/csbc2020/programacao-wit-md/
}

comunidade interessada, apresentando várias das nossas ações, aqui já citadas.

Ainda em novembro, o projeto foi convidado para participar do Fórum Goiano de Software Livre, realizado durante o $17^{\circ}$ Congresso Latino-americano de Software Livre e Tecnologias Abertas (Latinoware 2020), realizando um minicurso voltado para capacitação técnica intitulado "Python for Girls: Introdução a Programação com Meninas Digitais no Cerrado", que objetivou o ensino introdutório da linguagem de programação Python (uma das três mais populares do mundo [8]). Traz temáticas como estruturas de repetição, laços e vetores, contextualizando com a história de Ada Lovelace como a $1^{\text {a }}$ programadora. Como um dos destaques, a atividade contou com um participante inclusive de fora do Brasil, este que estava na Suécia devido à abrangência do evento.

Já no mês de dezembro, o referido projeto integrou também a XXI Feira de Ciência e Tecnologia do Instituto Federal Goiano - Campus Ceres, com participação ocorrida no dia 04/12, on-line, por meio da plataforma Youtube. Nessa oportunidade o projeto realizou uma oficina com o seguinte tema: "Lugar de mulher é onde ela quiser, inclusive na tecnologia!” (Fig. 4).

Durante o tempo de explanação, feito em suma por duas discentes da equipe do projeto, provocamos os participantes a refletirem sobre quem são e onde estão as mulheres de grande destaque em empresas de tecnologia; com protagonismo científico; destaque na política mundial; bem como mulheres brasileiras que ocupam cargos importantes.

Além disso, nesta ação foram apresentadas estatísticas sobre a participação de mulheres, no Brasil e no mundo, em cargos de chefia; na produção científica; nos cursos de computação; nas atividades profissionais de tecnologia da informação; bem como na pesquisa dedicada à computação. Houve também uma interação na plataforma $\mathrm{Kahoot}^{7}$, em que foi realizado um quiz de perguntas e respostas sobre mulheres na tecnologia, envolvendo internautas da Instituição e fora dela. Acerca do quiz, a maioria dos respondentes sentiu dificuldades em relacionar mulheres e seus feitos, incluso nos dias atuais, demonstrando que a presença das figuras femininas ainda são muitas vezes desconhecidas.

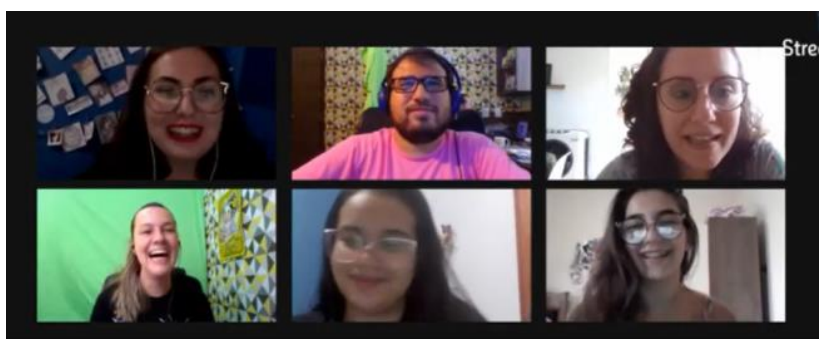

Figura 4: Equipe executora durante oficina na XXI Feira de Ciência e Tecnologia. Fonte: Própria (2020).

\footnotetext{
7 https://kahoot.it/
} 
Além das ações aqui abordadas, participamos ainda de diversos outros eventos a convite de projetos parceiros, abordando principalmente a história das mulheres na ciência, a participação feminina na informática, e até mesmo desenvolvendo ações de capacitação técnica, sendo destacadas ferramentas e linguagens já elencadas como Canva e Python. Deste modo, ocupamos espaços inclusive em eventos de grande renome não citados anteriormente, a exemplo da edição virtual e internacional da Campus Party Digital Edition ${ }^{8}$, figurando como uma das palestras com maior número de interessados no respectivo palco de transmissão.

\section{RESULTADOS E DISCUSSÃO}

Consideramos que o projeto obteve êxito na realização de suas atividades, adaptadas ao ambiente virtual. Isso porque, houve grande quantidade de participantes nas ações realizadas, que alcançaram as cinco regiões do Brasil, assim como outros países. Ao todo foram mais de 600 pessoas presentes, em mais de 20 atividades distintas, desde lives até palestras.

Pode notar-se também que o convite de participação em outros eventos importantes evidenciou a valorização e relevância das atividades que o projeto realiza e compõe junto com seus parceiros, o que foi reforçado pela participação no Fórum Meninas Digitais, sendo um dos projetos selecionados pelo quantitativo e êxito das ações promovidas.

Com os formulários de avaliação respondidos após os eventos também pudemos constatar que os participantes avaliaram obter bom aprendizado e/ou gostar da temática trabalhada. De acordo com os dados gerais coletados das atividades, $76 \%$ dos mesmos se sentiram "extremamente satisfeitos" com relação ao aprendizado adquirido nas atividades das quais participaram. Ademais, todos os respondentes responderam de forma unânime que indicariam as atividades para outras pessoas.

Além destes dados quantitativos, há ainda algumas considerações dos estudantes acerca das ações em que estiveram presentes, tais como: "Foi incrivel! Parabéns, agregou muito conhecimento", "Ótima iniciativa, continuem inspirando e compartilhando conhecimento!", ou ainda "Excelente abordagem das ministrantes, com interesse pelo público, rápida solução das dúvidas apresentadas e dinamismo na apresentação do conteúdo. Bom humor com sofisticação e conteúdo.".

\section{CONSIDERAÇÕES FINAIS}

Em decorrência do uso da web e suas ferramentas, a realização on-line das atividades conseguiu atingir pessoas de diferentes lugares do país e do mundo. Porém, como a Internet não é acessível para mais de $20 \%$ dos brasileiros [9], muitas pessoas não puderam participar das ações em questão dada à exclusão

\footnotetext{
${ }^{8}$ https://brasil.campus-party.org/
}

digital. Além desse fator, avaliamos ainda que o horário das ações talvez tenha prejudicado pessoas que, mesmo no contexto de pandemia, estiveram comprometidas com atividades de trabalho. Reconhecemos ainda que parte de nosso público alvo pode ainda não ter se interessado pelo tema das atividades oportunizadas.

Por fim, consideramos que, a despeito de nosso êxito, ainda existem muitas pessoas que não conhecem as histórias das mulheres na computação, sendo um dos eixos frequentemente trabalhados em todas as atividades desenvolvidas. De maneira que, projetos como este, a fim de incentivar meninas a seguir na área de TI, além de quebrar paradigmas impostos pela sociedade, permanecem importantes. Ademais, o expressivo número de convites e ações executadas, além de bons números de participações mesmo em tempos pandêmicos, reforçam o interesse da comunidade e dos desdobramentos sociais de projetos como este.

\section{REFERENCIAS}

[1] Pisa em Foco (2015). O que está por trás da desigualdade de gênero na educação?", OCDE, 03/2015 (Março), https://www.oecd.org/pisa /pisaproducts/ pisainfocus/PIF-49\%20(por).pdf.

[2] MEC (2019), Plataforma Nilo Peçanha: Resultados PNP 2019, http://resultados.plataformanilopecanha.org/2019/.

[3] SBC. (2018) Educação Superior em Computação Estatísticas - 2017. Sociedade Brasileira de Computação, https://www.sbc.org.br/documentos- dasbc/category/133-estatisticas

[4] Camargo, L. S., Braga, R. B., \& Braga, A. H. (2019). Meninas Digitais no Cerrado: Ações que empoderam e ajudam na permanência de meninas em cursos de TI. Anais do Computer on the Beach, 10(1), 871-878.

[5] Google (2020). Women Techmakers, https://www.womentechmakers.com/

[6] Ribeiro, K. D. S. F. M., \& Maciel, C. (2020). Meninas e Identidade Profissional: Percepções das Estudantes de Ensino Médio integrado em Informática sobre a área de Computação. Anais do Computer on the Beach, 11(1), 309-316.

[7] Maciel, C., \& Bim, S. (2017). Programa Meninas Digitais - ações para divulgar a Computação para meninas do ensino médio. Anais do Computer on the Beach, 7(1), 327-336.

[8] Tiobe Index (2020). Tiobe Index for December 2020, https://www.tiobe.com/ tiobe-index/

[9] PNAD (2020). PNAD Contínua TIC 2018, ftp://ftp.ibge.gov.br/ Trabalho_e Rendimento/Pesquisa_Nacional_por_Amostra_de_Domicilios_c ontinua/Anual/Acesso_Internet_Televisao_e_Posse_Telefone_Movel_2018/A nalise_dos_resultados_TIC_2018.pdf 